\title{
Determination of Kaempferol in extracts of Fusarium chlamydosporum, an endophyticfungi of Tylophora indica (Asclepeadaceae) and its anti-microbial activity
}

\author{
Pratibha Chaturvedi*1 ${ }^{1}$, Srikant Gajbhiye ${ }^{2}$, Soumen Roy ${ }^{1}$, Rohan Dudhale ${ }^{2}$, \\ and Abhay Chowdhary ${ }^{1}$ \\ ${ }^{1}$ Department of Virology, Haffkine Institute for Training, Research and Testing, Parel, Mumbai 400012, India \\ ${ }^{2}$ Department of Bacteriology, Haffkine Institute for Training, Research and Testing Parel, Mumbai 400012, \\ India *Corresponding author: pratibha. c@ rediffmail. com
}

\begin{abstract}
Present study describes the characterization and quantification of Kaempferol from methanolic and aqueous extracts of Fusarium chlamydosporum, an endophytic fungi isolated from Tylophora indica stem. MTT assay was done to examine its cytotoxicity. The CC50 values in both the extracts were $10 \mathrm{mg} / \mathrm{ml}$ concentration The methanolic extract also exhibited antibacterial activity against drug resistant strains of Psuedomonas aerugenosa and MRSA with an MIC of $500 \mu \mathrm{g} / \mathrm{ml}$ concentration. The HPTLC analysis exhibited the presence of Kaempferol at $0.21 \%$ in aqueous and $0.24 \%$ in methanolic extracts. Presence of Kaempferol in Fusarium chlamydosporum(endophytic fungi) in stem of Tylophora indica and its antibacterial activity are not well documented till date.
\end{abstract}

Keywords: Antibacterial, Anti cancerous, Endophytic fungi, Kaempferol, Tylophora indica

\section{Introduction}

Endophytic fungi live symbiotically with the majority of plants by entering their cells, are utilized as an indirect defense against herbivores. ${ }^{1,2}$ In exchange for carbohydrate energy resources, the fungus provides benefits to the plant which can include increased water or nutrient uptake and protection from insects, birds or mammals ${ }^{3}$. Once associated, the fungi alter nutrient content of the plant and enhance or begin production of secondary metabolites ${ }^{4}$. The change in chemical composition acts to deter herbivore by insects, by adult insects ${ }^{5}$ Endophyte-mediated defense can also be effective against pathogens and non-herbivory damage ${ }^{6}$. Some chemical defenses once thought to be produced by the plant have since been shown to be synthesized by endophytic fungi. The chemical basis of insect resistance in endophyte-plant defense mutualisms has been most extensively studied in the perennial ryegrass and involvement of three major classes of secondary metabolites are found i.e. indole diterpenes, ergot alkaloids and per amine. ${ }^{7,8,9}$

The terpenes and alkaloids are inducible defenses which act similarly to defensive compounds produced by plants and are highly toxic to a wide variety of phytophagous insects as well as mammalian herbivores. Two flavonoides of endophytic fungi of Gingko biloba have been isolated and well studied ${ }^{10}$. The presence of Kaempferol and quercetin has been shown in endophytic fungi isolated from Davidia involucrate Baill. The confirmation was done by HPLC analysis and its inhibitory effect was seen against Staphylococcus aureus, Bacillus subtilis and Escherichia coli ${ }^{11}$. Kaempferol has been identified in vivo and in vitro tissue culture of Tylophora indica ${ }^{12}$, so it was highly essential to examine that whether the endophytic fungi of this plant has the capacity to produce this flavonol, which is a antioxidant and anti-cancerous compound . Hence in the present investigation, we have examined the presence of Kaempferol in the endophytic fungi ,isolated from leaf and stem of Tylophora indica. Resistance against drugs has been developed in many bacteria in these days, so keeping this fact we also examined the methanolic and aqueous extracts of endophytes against drug resistance pathogens, which has given a wide spectrum

\subsection{EXPERIMENTAL}

\section{Material And Methods}

\section{1. 1Collection of Plant Material}

Plant material of Tylophora indica was collected from the Kelkar Farm House, Mulund(W), Mumbai India identified by botanist of Haffkine Institute and grown in Haffkine Institute campus till flourished growth was achieved.

1. 1. 2 Isolation and Identification of endophytic fungi from leaf and Stem of Tylophora indica

Isolation of endophytic fungi was carried out by the procedure of standardized and modified method described by Hallman et al. (2007) ${ }^{13}$. The samples (plants leaf \& stem) were rinsed gently in Sterile distilled water to remove dust and debris. Surface sterilization was done by $0.1 \%$ of $\mathrm{HgCl}_{2}$ according to the routine 
procedure. After proper washing, stem samples were cut into long $0.5-1 \mathrm{~cm}$ pieces, whereas leaves were cut into 3-4 $\mathrm{mm} \times 0.5-1 \mathrm{~cm}$ pieces under aseptic conditions. They were finally rinsed with deionized sterile distilled water to remove the sterilants and blot dried on sterile tissue paper. Surface sterilized stem\& leaf samples were crushed into sterile normal saline $(0.85 \% \mathrm{NaCl}$ Solution) and Taking $0.2 \mathrm{ml}$ of above crushing suspension was inoculated in to Sabouraud broth and kept it at room temp. for 5 days. . The identification of endophyte was carried out by using slide culture technique. The petri plates were sealed with parafilm , incubated at $27 \pm 2^{\circ} \mathrm{C}$ (room temp. ) for $4-5$ days under dark conditions and monitored every day. The isolated endophytic fungi was identified as Fusarium chlamydosporum from stem and from leaf Pyrenochaeta spp. (Fig1. c)

\subsubsection{Preparation of Extracts of endophytic fungi of Stem and leaf of Tylophora indica}

The cold extracts of methanolic as well as aqueous extracts of red and yellow fungi isolated from stem and leaf respectively were prepared at room temperature. The cold aqueous and methanolic extracts thus obtained were first filtered using Whatman No.1 filter paper, evaporated to drying. The dried extracts were weighed and subjected to HPTLC analysis for the characterization and quantification of Kempferol with standard Kaempferol (Sigma). (Fig.1)

\section{1.4 High Performance Thin Layer Chromatography (HPTLC)}

The HPTLC analysis of aqueous and methanolic extracts was carried out by using High Performance Thin Layer Chromatography. Inert gas was used as spray gas in CAMAG LINOMAT `121037 HPTLC equipment Toluene: Ethyl acetate : Methanol : Formic acid (30:15:1:2) was used as mobile phase(Rf- 0. 61). Scanning was done at $366 \mathrm{~nm}$ while $15 \%$ ethanolic ferric chloride was used as derivatizing agent. (Fig1.d-g).

\subsubsection{MTT Assay}

The cytotoxicity of both extracts was performed by using MTT assay. Prepared an MTT stock solution of $5 \mathrm{mg} \mathrm{ml-}{ }^{1}$ in phosphate buffered saline (PBS), $\mathrm{pH} 7.5$ and filter through a $0.22-\mu$ filter to sterilize and the small amount of insoluble residue were removed. Add $10 \mu \mathrm{l}$ of MTT (5mg ml-1) after $24 \mathrm{~h}$ of incubation and the cells were further incubated in incubator at $37^{\circ} \mathrm{C}$ for $3 \mathrm{hr}$. Then $100 \mu \mathrm{l} 0.04 \mathrm{M} \mathrm{HCl}$ in propan-2-ol to each well were added and mixed thoroughly to dissolve insoluble blue formazan crystals. The Plates were read on a micro-ELISA reader using a test wavelength of $570 \mathrm{~nm}^{18}$.

Cytotoxicity $\%=$ A-B/A X 100

$\mathrm{A}=\mathrm{O}$. D of untreated well; $\mathrm{B}=\mathrm{O}$. D of wells treated with plant extract

\subsubsection{Antibacterial assay of extracts of isolated endophytes of Tylophora indica}

The agar disc diffusion protocol was used for antibacterial assay . Sterile filter paper disc of $6 \mathrm{~mm}$ in diameter were loaded with 500, 300 and $200 \mu \mathrm{g} /$ disc using micropipette and were dried under laminar air flow hood. Streptomycin was used as a positive control. The loaded discs were placed in petri dish $(90 \mathrm{~mm}$ in diameter) containing sterile nutrient agar medium, thus evaluation for antibacterial assay of methanolic as also aqueous extracts were carried out against Methicillin-resistant Staphylococcus aureus (MRSA), Staphylococcus, Escherichia coli, Pseudomonas aeruginosa

\section{3. 1 Table 1. Antibacterial assay of extracts of endophytic fungi of Tylophora Indica}

\begin{tabular}{|c|c|c|c|c|c|}
\hline \multirow{2}{*}{ Name of endophyte extract } & \multicolumn{4}{|c|}{ Inhibitory zone $(\mathrm{mm})$} & \multirow{2}{*}{$\begin{array}{l}\text { Kaempferol } \\
\text { content } \%\end{array}$} \\
\hline & MRSA & Staphyloccocus & Escherichia coli & $\begin{array}{l}\text { Pseudomonas } \\
\text { aeruginosa }\end{array}$ & \\
\hline $\begin{array}{l}\text { Fusarium } \\
\text { chlamydosporum(Red) } \\
\text { Methanolic }\end{array}$ & $\begin{array}{ll}12 . & 5 \pm 0 \\
041 & \end{array}$ & $12 \pm 0052$ & 11. $5 \pm 0.096$ & - & $024 \pm 0.069$ \\
\hline $\begin{array}{l}\text { Fusarium } \\
\text { chlamydosporum }(\text { Red }) \\
\text { Aqueous }\end{array}$ & - & - & - & - & $0.21 \pm 0.031$ \\
\hline $\begin{array}{l}\text { Pyrenochaeta spp. } \\
\text { Methanolic extract }\end{array}$ & - & - & - & $13 \pm 0.054$ & - \\
\hline $\begin{array}{l}\text { Pyrenochaet spp. Aqueous } \\
\text { extract }\end{array}$ & - & - & - & - & - \\
\hline
\end{tabular}


Table 1. Depicts Kaempferol content and the anti bacterial assay of endophytic fungi isolated from Tylophora indica stem and leaf by Plate method at 500 $\mu \mathrm{g} / \mathrm{ml}$. $300 \mu \mathrm{g} / \mathrm{ml}$ and $200 \mu \mathrm{g} / \mathrm{ml} \mathrm{did} \mathrm{not} \mathrm{shown}$ any inhibition. $\pm S$. E. of mean values of three replicates

Figure 3. 1(a to g) Quantification and antibacterial assay of Kaempferol rich extracts of endophytic fungi isolated from Tylophora indica

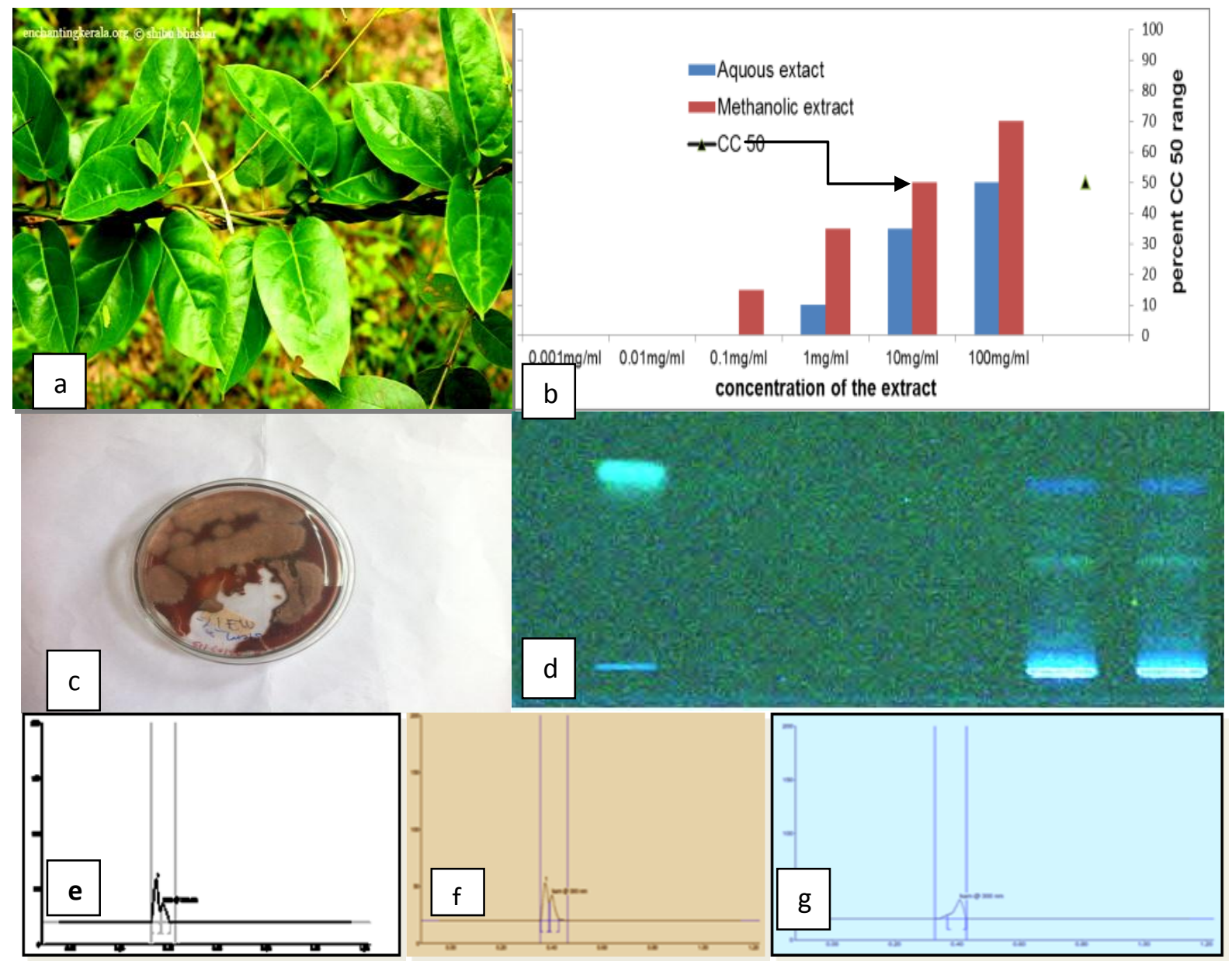

Fig.1. Isolation of Kaempferol from endophytic fungi of Tylophora indica(a-Plant of Tylophora indica b - MTT assay, c- Fusarium chlamydosporum grown with red pigment isolated from stem of $T$. indica, d- HPTLC analysis Fingerprinting of methanolic and aqueous extracts of Fusarium chlamydosporum for Kaempferol estimation with standard compound e-HPTLC Chromatogram of methanolic extract, f-HPTLC Chromatogram of aqueous extract of Fusarium chlamydosporum, g- with standard Kaempferol.

\section{Result}

An endophytic fungi is a fungal microorganism, which spends the whole or part of its life cycle colonizing inter and /or intra-cellular inside the healthy tissues of the host plants, typically causing no apparent symptoms of diseases. The endophyte of stem of Tylophora indica was identified as Fusarium chlamydosporum (given red pigment, Fig.1.c). whereas in leaf, it was confirmed as Pyorenochaeta spp. Toluene:Ethyl acetate:Methanol:Formic acid (30:15:1:2) was used as mobile phase (Rf-0. 61). Scanning was done at 366nm while $15 \%$ ethanolic ferric chloride was used as deravitizing agent. The High Performance Thin Layer Chromatographic analysis showed the presence of Kaempferol, 0. 21\% in aqueous and 0. 24\% in methanolic extract of Fusarium chlamydosporum (Fig. 1d, e, f, g), but it was absent in endophytic fungi of leaf. MTT assays depicts that they did not exhibit cytotoxicity in both extracts of Fusarium chlamydosporum below 10 $\mathrm{mg} / \mathrm{ml}$ concentration (Fig.1b) The methanolic extract also exhibited antibacterial activity against drug resistance bacteria like MRSA and drug resistant clinical isolates of Pseudomonas aeruginosa at $500 \mu \mathrm{g} / \mathrm{ml}$ concentration, 300 and $200 \mu \mathrm{g} / \mathrm{ml}$ did not show activity against any strain (Table 1). 


\section{1 DISCUSSION}

Evidence of plant-associated microorganisms found in the fossilized tissues of stems and leaves has revealed that endophyte-plant associations may have evolved from the time higher plants first appeared on the earth ${ }^{15}$ On the other hand, many discoveries have been made in isolating endophytic fungi, which have been shown to have the potential for de novo synthesis of various bioactive metabolites that may directly or indirectly be used as therapeutic agents against numerous ailments ${ }^{16,17}$. The possibility that endophytes biosynthesize associated plant compounds was first comprehended and published by Stierle et al. $(1993)^{18}$, following the highly indicated discovery of endophytic Taxomyces andreanae that produces the multi-billion dollar anticancer compound Taxol (generic name: paclitaxel), which was isolated from the Pacific yew tree Taxus brevifolia. Inspired by this discovery, numerous efforts have been made to identify endophytes as sources of associated plant natural products. In this line, we have examined the endophytic fungi of Tylophora indica whether it has a capacity to biosynthesize the secondary metabolite (Kaempferol) that is already reported in plant. We confirmed the presence of that compound by subjecting the methanolic as also the aqueous extracts to HPTLC analysis with standard compound and it was observed that Kaempferol was present $0.24 \%$ in methanolic and 0 . $21 \%$ in aqueous extract of Fusarium chlamydosporum. Another endophyte Pyrenochaeta spp obtained from leaf did not show the presence of Kaempferol.

The MTT Assay is a sensitive, quantitative and reliable colorimetric assay that measure viability, proliferation and activation of cells, was done on BHK-1cell line. The assay is based on the capacity of mitochondrial dehydrogenase enzymes in living cells on the capacity of mitochondrial dehydrogenase enzymes in living cells to convert the yellow water-soluble substrate 3-(4, 5-dimethylthiazol-2-yl)-2, 5 diphenyl tetrazolium bromide (MTT) into a dark formazan product that is insoluble in water. The amount of formazan produced is directly proportional to the cell number in a range of cell lines. MTT assay reveals that both extracts did not exhibit the cytotoxicity below $10 \mathrm{mg} / \mathrm{ml}(\mathrm{CC} 5010 \mathrm{mg} / \mathrm{ml})$. The production of beneficial secondary metabolites (including those produced by plants) by endophytes nurtures expectations of utilizing them as alternative and sustainable sources of these compounds. However, the commercial implication of production of desirable compounds by endophytic fungi still remains a future goal ${ }^{19}$. It is important to elucidate the metabolome in endophytes correlating to their associated plants on a case-by-case basis to understand how the biogenetic gene clusters are regulated and their expression is affected in planta and ex planta by environmental changes.

Although, Kumar et al. , $2011{ }^{20}$ have worked on endophytic fungi and Merlin et al. ,2012 ${ }^{21}$ have reported Taxol from endophyte Fusarium solenii of Tylophora indica, but the presence of Kaempferol in endophyte Fusarium chlamydosporum in stem of Tylophora indica and the antibacterial activity of extracts of Fusarium chlamydosporum against drug resistance bacteria are new findings. These all findings made this study more significance.

\section{Conclusion}

In conclusion, the results of present study revealed the presence of Kaempferol in aqueous as well as methanolic extracts of Fusarium chlamydosporum endophyte isolated from stem of Tylophora indica. The methanolic extract is potent as antibacterial agent

\section{Acknowledgement}

Authors are grateful to Dr Sarala Mennon, J. J. hospital , Byculla, Mumbai for identification of endophytes and all Haffkine institute collogues for kind help.

\section{References}

[1] S. Y. Strauss and A. R. Zangerl 2003, 77, 106, Plant-insect interactions in terrestrial ecosystems. In: Plant-animal interactions: an evolutionary approach (Herrera, C. M. \& Pellmyr, O., Eds. ). Malden: Blackwell Publishing. ISBN 978-0-632$05267-7$

[2] B. Wang and Y. L. Qiu, Phylogenetic distribution and evolution of mycorrhizae in land plants. Mycorrhiza 16 (5), 2006, 299-363.

[3] Y. Lekberg, R. T. Koide, Is plant performance limited by abundance of arbuscular mycorrhizal fungi? A meta analysis of studies published between 1988 and 2003". New Phytol 168 (1), 2005, 189-204.

[4] J. Dighton, 2003, Fungi in Ecosystem Processes. New York: Marcel Dekker. ISBN 978-0-8247-4244-7

[5] K. Clay, Fungal endophytes of grasses. Ann. Rev. Ecol. Systematics21, 1990, 275-297.

[6] A. E. Arnold, L. C. Mejia, D. Kyllo, E. I. Rojas, Z. Maynard, , N. Robbins, E. A. Herre, Fungal endophytes limit pathogen damage in a tropical tree. Proc. Natl. Acad. Sci. U. S. A. 100 (26), 2003, 15649-15654.

[7] V. Betina , Indole derived tremorgenic toxins. In: Mycotoxins Production, Isolation, Separation and Purification (Betina, V. ,ed. ). Developments in Food Science, 8. 1984, New York: Elsivier

[8] J. Rutschmann, P. A. Stadler, Chemical background. In: Ergot Alkaloids and Related Compounds (Berde, B. \& Schild, H. O. eds. ), 1978. Berlin: Springer-Verlag.

[9] D. X. Zhang, P. Nagabhyru, C. L. Schardl, Regulation of a Chemical Defense against Herbivory Produced by Symbiotic Fungi in Grass Plants. Plant Physiology 150 (2), 2009, 1072-1082. 
[10] Q. Min, X. Xu, H. Zhang, Hai-min C, Isolation and identification of two flavonoid-producing endophytic fungi from Ginkgo biloba L. Annals of Microbiology 60(1), 2010, 143-150.

[11] HeYing, Isolation and Identification of Endophytic Fungi Producing Flavonoids from Davidia Involucrate Baill Master'sthesis Microbiology,GuizhouUniversity . 2008

[12] P. Chaturvedi, P. Khanna and A. Chowdhury, 2012, In Vitro Production Of Secondary Metabolites of Medicinal Plant May ISBN no 978-3-659-12032-9 monograph Published from Lambert Publication.

[13] J. Hallmann, G. Berg G. B. Schulz, 2007, Isolation procedures for endophytic microorganisms, Springer Brelin Heidelberg. New York

[14] T. Mossman, Rapid colorimetric assay for cellular growth and survival: application to proliferation and cytotoxicity assays, $J$. Immun. Methods. 65 (1), 1983, 55-63.

[15] N. Radulovic, V. Stankov -Jovanovich, G. Stojanovic, A. Smelcerovic, M. Spiteller, Y. Asakawa ; Screening of in vitro antimicrobial and antioxidant activity of nine Hypericum species from the Balkans. Food Chem. , 103, $2007,15-21$.

[16] A. H. Aly, A. Debbab, J. Kjer, P. Proksch, Fungal endophytes from higher plants: a prolific source of phytochemicals and other bioactive natural products. Fungal Divers. , 41, 2010 1-16.

[17] R. N. Kharwar, A. Mishra , S. K. Gond, A. Stierle , D. Stierle, Anticancer compounds derived from fungal endophytes: their importance and future challenges. Nat. Prod. Rep. , 28, 2011, 1208-1228. 22. A.

[18] A. Stierle, G. A. Strobel and D. Stierle ; Taxol and taxane production by Taxomyces andreanae, an endophytic fungus of Pacific yew. Science 260, 1993, 214-216.

[19] S. Kusari S. , J. Kosuth, E. Cellarova , M. Spiteller, Survival-strategies of endophytic Fusarium solani against indigenous camptothecin biosynthesis. Fungal Ecol. , 4, 2011a, 219-223.

S. Kumar. , N. Kaushik . , R. Edrada-Ebel, R. Ebel and P. Proksch , Isolation, characterization and bioactivity of endophytic fungi of Tylophora indica. World Journal of Microbiology and Biotechnology 27, 2011, 3, $571-577$.

[21] J. Nomila Merlin, I. V. S. Nimal Christhudas, P. Praveen Kumar, M. Kumar,Taxol production by endophytic Fusarium solani LCPANCF01 from Tylophora indica J. Acad. Indus. Res. 1(5) 2012, 281. 